\title{
DESIGN AND FABRICATION OF MAGNETIC ENGINE
}

\author{
Ganesh Bairavan.P' ${ }^{1}$, Anojan. $\mathbf{T}^{2}$ \\ ${ }^{1}$ UG Student, Department of Automobile Engineering, Sathyabama University, Chennai, Tamilnadu, India \\ ${ }^{2} U G$ Student, Department of Automobile Engineering, Sathyabama University, Chennai, Tamilnadu, India
}

\begin{abstract}
The growing interest on the research in alternate fuels in India is influenced, mainly by fluctuating crude prices, limited oil reserves and the emission standards. The fossil fuels are likely to get exhausted very soon. We can now see the increasing use of electrical energy in almost all the fields. This is an effort to address an alternative method of producing energy without the use of fossil fuels called Magnetic Engine. Here, our aim is to produce power using the magnetic force which is generated between a permanent magnet and an electromagnet. The force which is basically of two types: Attractive force (different poles) and repulsive force (same poles). This might even replace the conventional IC Engines if developed successfully.
\end{abstract}

Keywords: Magnetic engine, Electromagnet, Permanent Magnet, Efficiency, Attraction and Repulsion.

\section{INTRODUCTION}

In today's World, it is practically impossible to imagine a life without IC Engines, which is one of the greatest man made inventions. IC Engines are primarily used in automobiles, which is a major mode of transportation to mankind. IC engines work mainly on gasoline and diesel which are derived from fossil fuels. The demand of automobiles keeps increasing as the Population increases. With this increase, the rate of fossil fuel consumption also increases. This creates a situation that brings up a need to switch to alternative sources of fuel to produce the power similar to that of IC engines. The challenge is not to create an engine that operates on an alternate fuel but to produce higher efficiencies. The next source of energy that strikes our minds is definitely electrical energy. Now-a-days, we can see automobiles that operate fully on electrical energy or a hybrid vehicle that operates both on electrical energy and an IC Engine. Speaking of electrical energy, it is quiet hard to store large amounts. Thus a method has to be developed that uses electrical energy in combination to produce better efficient engines.

This is where magnetism gets its spot. Magnetism exists in our universe, our Earth and our body. The magnetic engine is a system where a permanent magnet is attached to the piston which gets attracted by an electromagnet. The working of this magnetic engine is similar to that of a two stroke IC Engine. Power is developed once in every two stroke of the piston or one full revolution of the Flywheel. A connecting rod is used to convert the rotating motion of the flywheel into reciprocating motion of the piston via a crank. This magnetic engine can be applied in various machines other than automobiles, such as locomotives, golf cart.

Since this engine does not use fossil fuels, it does not pollute the environment thus being Eco-Friendly. Also the design of this electromagnetic engine is quiet simple because there is no need of combustion which eliminates the use of valves, water cooling system, fuel pump, fuel lines, air and fuel filters, inlet and exhaust manifolds etc. The power is generated using a system that contains a relay, an electromagnet, permanent magnet and batteries. The mechanical system consists of a reciprocating piston mechanism. The switching circuit is made using Arduino Uno chipset.

\section{WORKING PRINCIPLE}

The main principle behind the working of this engine is magnetism. There are two poles in a magnet, namely a north pole and a south pole. Magnetism is a physical phenomenon that arises when two or more magnetic bodies are brought near a magnetic field where the objects that produce fields either attract or repel each other ${ }^{[1]}$. The working of the magnetism is governed by the principle of "Like poles repel and unlike poles attract", that is, similar poles of different magnetic objects tend to move apart from each other while different poles of different objects tend to bring them close to each other.Here, permanent magnet is one magnetic object and the electromagnet acts as another magnetic object. So, the piston and the cylinder are designed in the required manner so that a force (due to magnetic fields) can be generated between them.

Basically, the working of this engine greatly resembles that of a two stroke IC engine where there is one power stroke for every two strokes/reciprocation of the piston or one full revolution of the flywheel. The movement of the piston is achieved with the help of the magnetic attraction between the Neodymium Iron Boron $(\mathrm{NdFeB})$ Magnet (Permanent magnet) and the energized electromagnet. When the piston is at the top of the cylinder, the electromagnet is deenergized by default. When the engine is started (Power supply is given), the electromagnet gets the electric power and hence gets energized becoming a magnet. This now attracts the permanent magnet which in turn draws the piston downwards. The electric supply is provided using a battery set and is controlled by an Arduino Uno chipset which is used to set the frequencies for the pulse to go high 
and low. When the pulse is high, the power is supplied and when it goes low, the supply gets cut-off. Now, as the piston reaches the bottom and the power is cut-off, the energy stored in the flywheel makes the piston go back to its original position that is to the top, thereby completing the two strokes. The power is generated during the first strokewhen the piston is pulled down by the magnetic force. This process is repeated and thus the energy produced is transferred to the flywheel which stores it for further applications.

The permanent magnet is fixed on the head of the piston using strong adhesives. The electromagnet is made of Copper coils. When the supply is given, the coil gets energized and hence gets converted into an electromagnet. The power supply to the coil is regulated with the help of a relay. The relay gets power every time the frequency of the chipset goes high there by completing the circuit and energizing the electromagnet.

\section{DESIGN CALCULATIONS}

Input voltage $=24 \mathrm{~V}$

Input current $=0.6 \mathrm{~A}$

Input Power $=$ Voltage $\times$ Current $=\left(24^{*} 0.6\right)=14.4 \mathrm{~W}$

Max. Force exerted by electromagnet on piston,

$$
\mathrm{F} 1=\left(\mathrm{N}^{2} \mathrm{I}^{2} \mathrm{KA}\right) / 2 \mathrm{G}^{2}
$$

Where,

$\mathrm{N}=$ number of turns $=600$

$\mathrm{I}=$ Current flowing through coil $=0.6 \mathrm{~A}$

$\mathrm{K}=$ Permeability of free space $=4 \pi \times 10^{-7}$

$\mathrm{A}=$ Cross-sectional area of electromagnet (radius $\mathrm{r}=0.0325$

$\mathrm{m})$

$\mathrm{G}=$ Least distance between permanent and electromagnet $=$ $0.005 \mathrm{~m}$

On substitution, we get,

Max. Force F1 $=10.80 \mathrm{~N}$

Force exerted by permanent magnet,

$$
\mathrm{F} 2=\left(\mathrm{B}^{2} \mathrm{~A}\right) / 2 \mu_{0}
$$

Where,

$\mathrm{B}=$ Flux density $(\mathrm{T})$

$A=$ Cross-sectional area of magnet (radius $r=0.0195 \mathrm{~m}$ )

$\mu_{0}=$ Permeability of free space $=4 \pi \times 10^{-7}$

Now, Flux Density B is given by:

$$
\mathrm{B}=\mathrm{Br} / 2 \times\left[(\mathrm{D}+\mathrm{z}) /\left(\mathrm{R}^{2}+(\mathrm{D}+\mathrm{z})^{2}\right)^{0.5}-\mathrm{z} /\left(\mathrm{R}^{2}+\mathrm{z}^{2}\right)^{0.5}\right]
$$

Where,

$\mathrm{Br}=$ Remanence field $=1.21 \mathrm{~T}$

$\mathrm{z}=0.005=$ distance from a pole face

$\mathrm{D}=0.012 \mathrm{~m}=$ thickness of magnet

$\mathrm{R}=$ semi-diameter of the magnet $=0.0195 \mathrm{~m}$

On substitution we get flux density, $\mathrm{B}=0.2481 \mathrm{~T}$

Now substituting $B$ in the equation of force, $F 2=29.25 \mathrm{~N}$
Since, force $\mathrm{F} 1$ and $\mathrm{F} 2$ are repulsive, Total force $\mathrm{F}=\mathrm{F} 1+$ F2

Therefore, $\mathrm{F}=40.05 \mathrm{~N}$

$$
\text { Torque } \mathrm{T}=\mathrm{F} \times \mathrm{r}
$$

Where,

$\mathrm{F}=$ total force on piston

$\mathrm{r}=$ crank radius $=0.01 \mathrm{~m}$

Torque $\mathrm{T}=0.4005 \mathrm{~N}-\mathrm{m}$

Mass of Fly wheel M,

$$
\omega=(2 \pi N) / 60
$$

Where,

$\mathrm{N}=$ speed $=200 \mathrm{rpm}$

Therefore $\omega=20.94 \mathrm{rad} / \mathrm{s}$

Energy stored on flywheel $\mathrm{E}=\mathrm{T} \times \theta$

Where,

$\theta=$ Angle of rotation $=180^{\circ}=\pi$ radians

$\mathrm{T}=$ torque

On substitution, we get energy stored, $\mathrm{E}=1.258 \mathrm{~J}$

Also

$$
\mathrm{E}=0.5 \times \mathrm{I} \times \omega^{2}
$$

Where,

$\omega=$ angular velocity

I = moment of inertia of flywheel

On substitution we get moment of inertia,

$\mathrm{I}=5.73 * 10^{-3} \mathrm{Kg}-\mathrm{m}^{2}$

Moment of inertia,

$$
\mathrm{I}=0.5 \times \mathrm{m} \times \mathrm{r}^{2}
$$

Where,

$\mathrm{r}=$ radius of fly wheel $=\mathrm{m}$

$\mathrm{m}=$ mass of fly wheel

On substitution, we get $\mathrm{m}=1.586 \mathrm{Kg}$.

Output power, $\mathrm{P}=(2 \pi \mathrm{NT}) / 60$

Where,

$\mathrm{N}=$ speed $=200 \mathrm{rpm}$

$\mathrm{T}=$ Torque $=0.4005 \mathrm{~N}-\mathrm{m}$

On substitution, we get,

Output power $\mathrm{P}=8.388 \mathrm{~W}$

Efficiency $=($ Output/Input $) \times 100=(8.388 / 14.4) \times 100$

Therefore,

Efficiency $=58.19 \%$

\section{COMPONENTS AND THEIR MATERIALS}

\subsection{Cylinder}

Cylinder is the part of the engine inside which the piston moves up and down. Unlike a conventional IC engine, there is no need of any fuel or air for the operation of this 
magnetic engine. So the design of the cylinder is quiet easy since there is no need for fuel and air intake, spark plug, etc. The temperature inside the cylinder during the running conditions is also quiet low, which means that no fins are required. Thus, the cylinder is a simple cube like structure with a bore in the middle for the piston. The cylinder is made of Aluminum which is nonmagnetic, light weight and strong material.

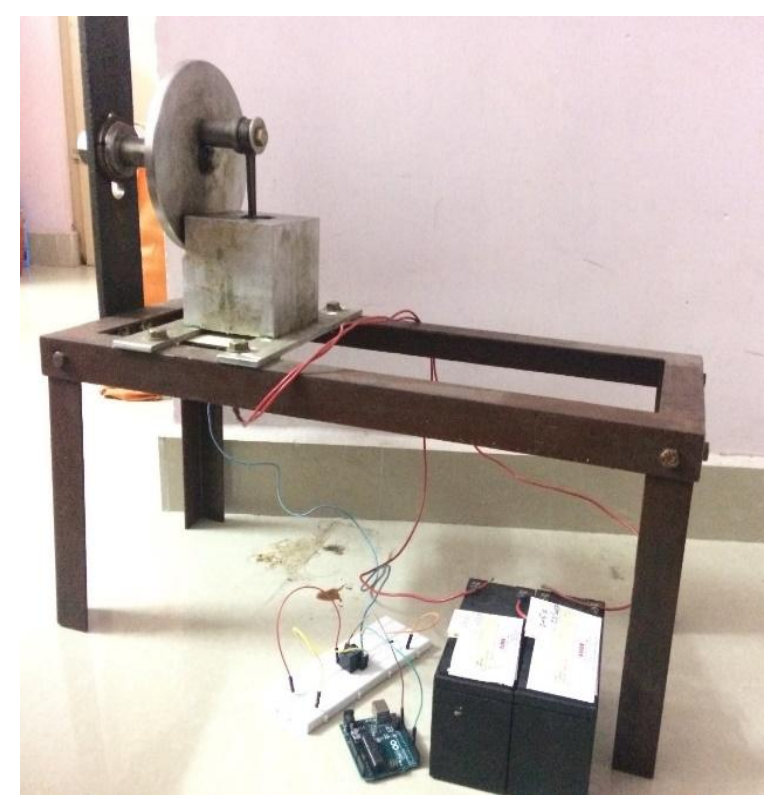

Fig -1: Magnetic Engine setup

\subsection{Piston}

The piston that we have used is similar to the ones used in IC engines. Piston is made out of aluminum as well because the NdFeB magnet has to be attached on top of the piston head which shouldn't get attracted by the piston itself. The small end of the connecting rod is connected to the hollow side of the piston and the big end is connected to the crankshaft. The crankshaft is connected to the flywheel. The crank shaft, connecting rod and piston put together convert the linear reciprocation into rotating motion of the flywheel.

\subsection{Flywheel}

Flywheel is also made up of aluminum. It converts the reciprocating energy into rotating energy. It helps regulate the engine's rotation, maintaining it at a steady speed. They can resist changes in rotational speeds since they have a significant moment of inertia. The flywheel acts as a reservoir that stores the rotational energy.

\subsection{Electromagnet}

A coil is formed using insulated solid copper wire which is wound around a core. When electricity is passed through this coil, the coil gets energized and a magnetic field is generated. A winding is usually referred as one loop of the copper wire around the core.It is always better to coat the coils with varnish or wrap them with insulating tape as they provide enhance their insulating properties.

\subsection{Relay}

Relay is an instrument similar to a switch that is operated electrically. A magnetic field is created when the current flows through the coil which brings the lever into contact by attracting them. Just like any switch, relays also have two positions that is on and off.

\subsection{Arduino Uno}

Arduino Uno is a microcontroller board. We have chosen to use this for adjusting the time/frequency of the electrical pulse that is generated to control the power supply to the electromagnet. The board is programmable and for this engine, a program of just four lines is required. This is a good and suitable replacement for the conventional IC 555 timer and resistors setup.

\subsection{Battery}

We are using the Lead-Acid Battery in this engine for supplying the electrical power required.

\section{ANALYSIS}

The magnetic engine was successfully designed and fabricated. This was tested and the following graphs were obtained.

The graph below (chart 1) shows the variation of force with current. It is seen that the magnitude of force increases with increase in current. It is also evident that the force is directly proportional to current.

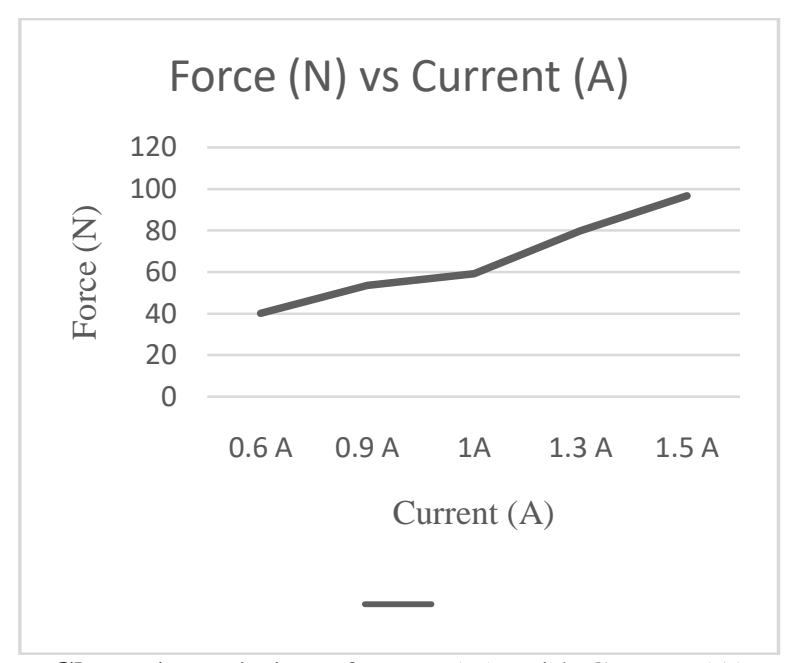

Chart-1: Variation of Force (N) With Current (A)

The variation of efficiency with input power is shown in chart 2. The maximum efficiency is obtained for the least input value. The efficiency then drops to a limit and then increases again. 


\section{Efficiency vs Input power.}

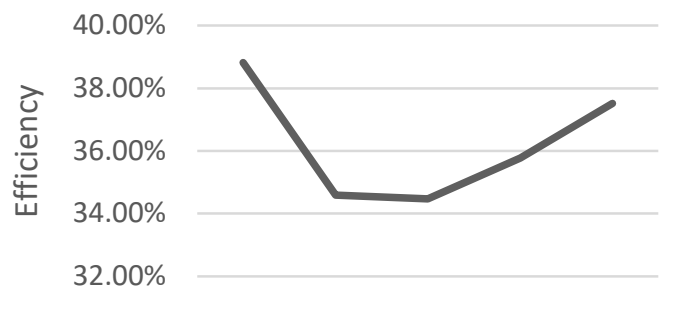

21.6 W32.4 W 36 W 46.8 W 54 W

Input Power (W)

Chart-2: Variation of efficiency (\%) with input power (W)

\section{RESULTS AND DISCUSSION}

- The prototype of the magnetic engine was successfully designed and fabricated.

- It is driven with the help of magnetic energy and electricity only. So, no fuel consumption is required.

- It creates no pollution and is eco-friendly.

- This engine produces power once in every two stroke of the piston.

- We obtained a maximum efficiency of $38.824 \%$ for an input power of $21.6 \mathrm{~W}$.

- We can achieve better efficiency and power output of the engine if the following corrections are made:

> The windings are hand wound with the help of lathe machine. This leads to increase in air gap which leads to weaker magnetic field.

$>$ Laminate the windings.

> Relay offers resistance which results in lesser force.

> The fabrication is not very precise and might have some misalignments.

\section{CONCLUSION}

The magnetic engine has several advantages over the conventional IC engines. The magnetic engine with some other modifications in the design, shape and size, much higher outputs can be achieved making it a suitable replacement for the IC engines.

Since the magnetic engine does not require combustion process to produce power, the fuel tank, fuel supply line, injectors, Fuel pump and fuel filter, air filter, intake manifolds, etc can be removed from the engine resulting in much lighter engine. Also the magnetic engine does not produce so much heat thereby eliminating the need of a cooling system. In case of multi cylinder high power magnetic engines, conventional transmission systems can also be implemented as the process after getting the power at the flywheel remains the same.

When there are advantages, there will also be disadvantages. Some of the disadvantages of this magnetic engine are high initial cost, setup and power source. The initial cost which includes a permanent magnet and an electromagnet might turn out to be expensive. Since the power supply is given using batteries, they tend to go low very frequently. They have to be recharged quiet frequently which might turn out to be a little disturbing. Also use of many batteries in series can increase the power of the engine but also increase the net weight of the setup.

The prototype of this magnetic engine is built to produce a power stroke once in two strokes of the piston utilizing either the attractive force or repulsive force between the magnets. This can be modified in such a way that the power is produced in every stroke by changing the polarity of the electromagnet by changing the direction of the current flow. This will definitely increase the net power output thereby increasing the efficiency of the engine.

\section{REFERENCES}

[1]. Abil Joseph Eapen, AbyEshowVarughese, Arun T.P, and Athul T.N, "Electromagnetic Engine", IJRET, 2014

[2]. AmarnathJayaprakash, Balaji G., Bala Subramanian S. and Naveen N., "Studies on Electromagnetic Engine", IJDR, 2014

[3]. DruvaKumar.L Jathin. P, Gowtham. S, Manikandan. P, "Future Energy Redefined by Magnetics", IJAREEIE, 2012

[4]. V. Ganesan; Tata McGraw-Hill Education; Internal Combustion Engines

[5]. Leland W. Gifford; "Reciprocating electromagnetic engine"; US 5457349 A

[6]. MentaSudheer, KonduruVasu and KalahstiSirishaVamsi, "Magnetic Piston Engine", IJMERR, 2014

[7]. K.S. Nesamani; Institute of Transportation Studies, University of California; "Estimation of Automobile Emissions and Control Strategies in India" (2009)

[8]. C. A. Oprea, L. Szabó, C. S. Martis, "Linear Permanent Magnet Electric Generator for Free Piston Engine Applications", Electrical Machines (ICEM), 2012

[9]. RadhakrishnaSheshalyengarTogare; "Magnetic Pistons Engine"; 2010;US 7,667,356 B2

[10]. Ramanan. M, Balasubramanian. M, and Ilaiyaraja. S, "Experimental Investigation on Magnetized Piston Powered Engine", IOSR-JMCE, 2014

[11]. S.S. Rattan; Tata McGraw-Hill Education; Theory of Machines

[12]. J. Rithula, J. Jeyashruthi and Y Anandhi, "Electric Vehicle with Zero-fuel Electromagnetic Automobile Engine",IJERT, 2013

[13]. Sherman S. Blalock; "Electro-magnetic reciprocating engine"; US 4317058 A

[14]. Shirsendu Das, "An Electromagnetic Mechanism Which Works Like an Engine", IJETT, 2013

[15]. C. Sudhakar, K. Premkumar, K.Vijith, S.Balaji, "Emissionless Engine by using ElectroMagnet", IJRAET, 2013

[16]. 20060131887 A1 (US), Feb 15, 2006, Magnetically Actuated Reciprocating Motor and Process Using Reverse Magnetic Switching, 2006

[17]. 20080012432 A1 (US), Jun 11, 2007, Magnetic Pistons Engine, 2008 
[18]. 3676719 (US), July 22, 1971, Electromagnetic Motor with Plural Reciprocating Members, 197

[19]. 4317058 (US), Dec 28, 1979, Electro-magnetic

Reciprocating Engine, 1982

[20]. www.livescience.com/38059-magnetism.html 